\title{
Sustainable Agricultural Practices in Climate Change Adaptation and Mitigation: The Case of India
}

\author{
I. Sundar \\ Associate Professor of Economics, Directorate of Distance Education, Annamalai University,India
}

Received date: 19 April 2018, Accepted date: 15 June 2018, Online date: 29 June 2018

Address For Correspondence:

I. Sundar, Associate Professor of Economics, Directorate of Distance Education, Annamalai University, India

Copyright (C) 2018 by authors and American-Eurasian Network for Scientific Information. This work is licensed under the Creative Commons Attribution International License (CC BY). http://creativecommons.org/licenses/by/4.0/

\section{(c) (i) Open Access}

\begin{abstract}
Adaptation and mitigation in the agriculture sector aim at addressing the negative impacts of climate change and making use of the opportunities that often come with a changing climate. The overall aim of adaptation and mitigation in agriculture is to reduce farmers' vulnerability and improve their adaptive capacity. This paper deals with sustainable agricultural practices in climate change adaptation and mitigation. It outlines the climate change impacts scenario in Indian agriculture, and need for sustainable agriculture in developing climate change adaptation practices and policy options. This paper makes a special note on sustainable climate change mitigation options in agriculture and sustainable climate change coping mechanism. This paper concludes with some interesting findings along with policy suggestions.
\end{abstract}

\section{KEY WORDS}

Climate change, sustainable agriculture, adaptation, mitigation, coping mechanism.

\section{INTRODUCTION}

Climate change has created challenges for the agricultural sector - and will continue to do so. Climate change-induced increases in temperatures, rainfall variation and the frequency and intensity of extreme weather events are adding to pressures on global agricultural and food systems. Climate change is expected to negatively affect both crop and livestock production systems in most regions, although some countries may actually benefit from the changing conditions. The changing climate is also adding to resource problems, such as water scarcity, pollution and soil degradation.

Hatfield, J., K. Boote, P. Fay, L. Hahn, et al. [5] and K. Boote, P. Fay, L. Hahn, C. Izaurralde, et al. [8] note that crop responses to a changing climate are generally affected by the interplay of three key factors: (1) rising temperatures, (2) changing water resources, and (3) increasing carbon dioxide concentrations. Generally, warming causes plants that are below their optimum temperatures to grow faster, increasing overall activity and productivity. This however is not always positive; for some crops, like cereal crops, warmer temperatures and faster growth means less time for the grain itself to grow and mature, reducing yields.

Müller et al., FAO and World Bank, caution that local food security may be particularly at risk in arid and semi-arid ecosystems, in fragile mountain and coastal areas and on small islands consequent upon climate change. In general, it can be said that the effects of climate change on agriculture will be felt most in the developing world and in least developed countries. Lobell et al. and Schneider report that most serious effects on agricultural production are projected for South Asia, southern Africa, the West African Sahel and Brazil. 
Climate Change Impacts Scenario in Indian Agriculture:

Agriculture is one of the largest contributors to India's GDP, approximately $20 \%$. It is the main source of livelihood for almost $60 \%$ of the country's total population. The impacts of climate change on agriculture will therefore be severely felt in India. As per the report by GoI, Guiteras and OECD the projected scenario of a 2.5 ${ }^{\circ} \mathrm{C}$ to $4.9{ }^{\circ} \mathrm{C}$ temperature rise in India, results in rice yields drop by $32 \%-40 \%$ and wheat yields by $41 \%-52 \%$. This would cause GDP to fall by $1.8 \%-3.4 \%$.

Despite the gloomy predictions about the negative impacts for India's agricultural sector, climate change is generally also expected to bring opportunities, in the form of production gains through the $\mathrm{CO}^{2}$ fertilization effect or the expansion of cultivated land to higher altitudes and northern latitudes. IFPRI (2009) and UNFCCC (2009) noted that to date all climate change projections have been accompanied by uncertainty - not primarily concerning trends but extent.

\section{Need for Sustainable Agriculture:}

Sustainable agriculture recognizes the complex interactions between soil, water, plants, animals, climate, and people. The overreaching goal of sustainable agriculture is to integrate all of these factors into a production system that is appropriate for the environment, people, and local economic conditions

The importance of sustainable agriculture is increasingly realized world over. This awareness has come to the centre stage of global debate as a result of degradation of natural resources and environment. Further the impact of climate change aggravates the agriculture yield. Hence, there is a need to examine the concept of sustainable agriculture. According to Donald, L.P. and Donald, L. W. [3] sustainable agriculture is farming practice, which meets the rising demand over the indefinite period at economic, environmental and other social costs consistent with rising income. Thus it explains an agrarian system should produce adequate food of high quality along with environmental safe. As per the views of Jones, M.J. [7] sustainable agriculture is a process of an extension of current concern about food security into the future and thereby food production is either maintained or increased, but it should be declined.

Regarding environmental dimension, Altieri, M. A., [1], notes that sustainable agriculture is said to be the ability of an agro eco-system to maintain production through times in the face of long term ecological constraints and socio-economic pressure. It is clear from this statement that food production could be maintained on a par with the increase in population. However, the agro-ecosystem should not be deteriorated with the application of anti-environmental inputs in the process of cultivation, necessitating the need of low input sustainable agricultural practices.

The important of sustainable agriculture can be traced that it enhances the environmental quality and the resource base upon which agriculture depends. According to Shaller, N., [12] this form of agriculture is expected to provide basic human food and fibre needs which is economically viable and socially desirable a long with enhancing the quality of life of farmers and society as a whole.

\section{Need for Sustainable Agricultural Practices in Climate Change Adaptation:}

The sustainable agriculture practices are highly required in the context of climate change. Climate change adaptation in agriculture practices is the major focus of the sustainable practices. In this context, an analysis of the existing adaptive capacity and assets of a given target group is therefore a crucial starting point, as can be seen in the following example. Historically, small-scale farmers in drought-prone areas of the Sahel have always autonomously adapted in the short and long term to changes in climate. They have used drought-adapted crops such as sorghum and adjusted their production practices, spreading risk, by staggered sowing, weeding fields promising the highest yield first, or using hand-dug wells to irrigate their fields in the event of low rainfall. However, these farmers are often not aware of the overall scale of climate change and of the fact that their adaptation practices may not be able to cope with current climate change impacts, thereby threatening their ability to sustain their family's livelihood.

It could be noted that adaptation in agriculture in the context of climate change must include creating awareness and understanding of climate change and its risks at all levels, in order to enable farmers and rural communities to effectively identify and utilize their available adaptive capacity.

\section{Sustainable Agriculture Practices required for Climate Change Adaptation:}

The policy adaptation option on promotion of agricultural research is very essential towards achieving sustainability in agriculture development. In this context efforts could be made to develop crop and livestock technologies in the form of better heat and drought-resistant crops. Further there is a need to enhance seed banks, encouraging the transfer or adoption of locally important innovations particularly water harvesting systems and making use of complementarities between public and private agricultural research.

The sustainable adaptation option should promote crop and livestock diversification and agro biodiversity and avoiding monocultures. In this context there is a need to reduce the risk of crop failure by advising farmers to grow drought-resistant food crops such as cassava, millet, or sorghum. 
The promotion of adoption technologies is one of the aspects of sustainable agriculture climate change adaptation. The success of this approach depends on modernizing farm operations and using adapted seeds, increasing efficiency of water infrastructure and water use, providing opportunities to reduce direct dependence on natural factors such as precipitation and runoff and reducing vulnerability to climatic variations and natural disasters and improving irrigation systems.

The climate change adaptation in achieving sustainable agriculture depends on dispersion of information on conservation management practices. It aims at protecting fields from water and wind erosion, using management practices that reduce dependence on irrigation in order to decrease water consumption without reducing crop yields and changing tillage practices in the form of zero tillage on formerly overused/ depleted land.

The sustainable agriculture can be achieved in the context of climate change by the way of promoting investment in better information and forecasts. In this context efforts could be made towards improving communication technologies in order to improve access to and handling of information, refining modeling techniques that bring high-quality short-term forecasts to many parts of the world and supporting the diffusion of information to help interpret forecasts in terms of their agronomic and economic implications.

\section{India's National Mission for Sustainable Agriculture:}

The National Mission for Sustainable Agriculture is one of the eight missions in India's National Action Plan on Climate Change. It stresses how crucial agriculture is to India's economy and the livelihood of its people, since the agriculture sector supports more than half the country's population of over 1 billion people. The mission focuses on four areas that are relevant for the endeavours of India's agricultural sector to adapt to climate change in the form of: dryland agriculture, risk management, access to information and use of biotechnology

Priority actions for sustainable dryland agriculture with particular relevance to climate change adaptation are required. These include: developing drought and pest-resistant crop varieties, improving methods to conserve soil and water, conducting stakeholder consultations, training workshops and demonstration exercises to help farming communities share and disseminate agro-climatic information and providing financial support to enable farmers to invest in and adopt relevant technologies to overcome climate-related stresses.

Some of the priority actions in the field of agricultural risk management are required towards achieving sustainable agriculture productivity. They are: strengthening current agricultural and weather insurance mechanisms, development and validation of weather derivative models by insurance providers, ensuring access to archived and current weather data, creating web-enabled, regional language based services to facilitate weather-based insurance, developing geographical information systems and remote sensing based methodologies for detailed soil resource mapping and land use planning at the level of a watershed or river basin, mapping vulnerable eco-regions and pest and disease hotspots and developing and implementing regionspecific contingency plans based on vulnerability and risk scenarios.

\section{Climate Change Adaptation and Sustainable Agriculture production:}

There are several options for adaptation to climate change that can safeguard sustainable agricultural production. One is to enhance existing production systems by using different practices in the form of changing sowing patterns and new technologies in terms of irrigation systems are adapted varieties. Another option in achieving sustainable production in agriculture is to use a different production system that is better suited to the changed climatic and environmental conditions.

The pre supposes using new or existing varieties that are adapted to extreme environmental conditions is the sustainable agriculture practice in the context of climate change. They also provide the genetic material for agricultural research needs to develop technical innovations. The another sustainable agriculture practice option is to promote agro biodiversity, i.e. the genetic resources for food and agriculture, support natural ecosystems capacity to mitigate the impact of extreme events by the way of inclusion of woodlots, and protection of water resources, or wetlands.

Before changing to different production systems, it is important to explore market demands and ensure there are opportunities for marketing the produce. Researching and utilizing existing local varieties that are adapted to extreme environmental conditions is another important measure of sustainable agriculture practice. These varieties also constitute a fundamental part of the genetic material for agricultural research.

Sustainable agricultural practices often derive from efforts and experience that farmers acquire over time in adapting to different climatic conditions - be it short or long-term changes in weather and climate. The justification for calling any measure an adaptation option rather than just good 'old' agricultural practice lies in the process of identifying a certain measure by taking climate change into account. 
Sustainable Agriculture Practices in the Context of Climate Change:

Many sustainable agricultural practices proposed to and such practices that can be used separately or in combination to adapt to local climatic changes. The sustainable cropping system is required in the context of climate change adaptation. These include: drought-tolerant crops such as millet instead of corn and varieties, early maturing varieties and salt-tolerant varieties.

The sustainable measures on crop diversification, in the form of off-season crops, short season crops, fruit cultivation and crop management can be practiced. The sustainable measures include: enhancing crop rotation practices, changing cropping patterns, improving seed storage, integrating trees and bushes to reduce water runoff and erosion and flood protection, maintaining agro biodiversity to conserve frost tolerant species and varieties and applying soil and water conservation measures, by the way of contour cropping and terracing.

The sustainable inputs are required for crop cultivation in the context of climate change. These include: using supplementary feeds and concentrates, using adapted livestock breeds, constructing livestock shelters, using supplementary feeds, animal management, continuously matching stock rates with pasture production, changing grassland cutting frequency, restricting extensive livestock farming, enhancing animal welfare, by the way of vaccinating animals to protect them and reduce the spread of disease, moving herds from waterlogged fields, continuously matching stock rate with pasture production, increasing feed reserves, designating special areas for livestock grazing and protecting steep slopes by avoiding overgrazing so that that the vegetation cover remains stable.

Agricultural extension plays a crucial role in promoting sustainable agricultural productivity, by the way of increasing food security, improving rural livelihoods, and promoting agriculture as an engine for pro-poor economic growth. Smit and Skinner note that agricultural extension services be strengthened in the form of: a transfer from theory into practice must take place to enable research results and innovations to find their way into the field.

In order to promote agriculture sustainability in the context of climate change, insurances can support farmers in their adaptation process and prevent them from falling into absolute poverty. Apart from stabilizing household incomes by reducing the economic risk, insurance can also enhance farmers' willingness to adapt, to make use of innovations and invest in new technologies. Additional credit insurance schemes may increase the creditworthiness of farmers applying for loans and thus support investment in agricultural production.

The practicing of conservation agriculture is one of the aspects of sustainable practice in the context of climate change. Resource conserving technologies involving zero or minimum tillage with direct seeding, permanent or semi-permanent residue cover, and crop rotations have the potential to improve the efficiency of use of natural resources, including water, air, fossil fuel, and soil. Such resource conserving technologies constitute the sustainable agriculture practice.

The technologies can improve the sustainability of the cropping system by conserving the resource base and higher input use efficiency and also mitigating GHG emission. The changes in crop management system according to the changing scenario of climate change are the sustainable practice. Crop management, such as short, medium, and long duration variety; change in sowing time, which includes early as well as late sowing relative to current sowing time; increasing the seed replacement rate by the farmers; and change in irrigation patterns and fertilizer application for increased input use efficiency, should be pursued.

The sustainable agriculture practice in the form of crop diversification is highly required in the context of climate change. It could be noted that diversification of crops and livestock varieties, including the replacement of plant types, cultivars, hybrids, and animal breeds with new varieties intended for higher drought or heat tolerance, has been advocated as having the potential to increase productivity in the face of temperature and moisture stresses. Diversity in seed genetic structure and composition has been recognized as an effective defense against disease and pest outbreak and climate hazards.

The sustainable agriculture practice in the form of adjusting cropping season is highly required in the context of climate change adaptation. It could be noted that adjustment of planting dates to minimize the effect of temperature increase- induced spikelet sterility can be used to reduce yield instability, by avoiding having the flowering period to coincide with the hottest period. It could be noted that adaptation measures to reduce the negative effects of increased climatic variability as normally experienced in arid and semi-arid tropics may include changing the cropping calendar to take advantage of the wet period and avoiding extreme weather events during the growing season.

The sustainable climate change adaptation measures can be observed by the way of changing crops and production can be enhanced by improved crop management, improved adverse climate tolerant varieties, improved seed sector, using technology dissemination mechanisms, making available capital and information, which are the key reasons for yield gaps. Watershed management programme can yield multiple benefits. Such strategies could be very useful in future climatic stress conditions.

The sustainable farming practices in the context of climate change can be evolution of location specific fertilizer practices, improved fertilizer supply and distribution system, improved water and fertilizer use. Early warning system and crop insurance: Improved risk management can be carried out through early warning 
system and crop insurance policies that encourage crop insurance and can provide protection to the farmers if their farm production is reduced due to natural calamities.

The sustainable climate change adaptation can be practiced in agriculture in the form of water management. Water harvesting techniques and micro catchments are extremely beneficial in increasing biomass production in arid climates. Waste water and solid waste in agriculture should be recycled as freshwater supplies are limited and water has competing uses, and it would become even more constrained in changed global climate.

\section{Sustainable Climate Change Mitigation Options in Agriculture:}

The sustainable climate change mitigation is very important in achieving agriculture production. Agriculture has the potential to cost-effectively mitigate GHGs through changes in agricultural technologies and management practices. Mitigation of GHG emission from agriculture can be achieved by sequestering carbon in soil and reducing methane and $\mathrm{N} 2 \mathrm{O}$ emissions from soil through change in land use management. The sustainable climate change mitigation options in agriculture include changing crop mixes to include more plants that are perennial or have deep root systems increases the amount of carbon stored in the soil, cultivation systems that leave residues and reduce tillage, especially deep tillage, encourage the buildup of soil carbon, shifting land use from annual crops to perennial crops, pasture, and agro-forestry increase both above- and below-ground carbon stocks and changes in crop genetics and the management of irrigation, fertilizer use, and soils can reduce both $\mathrm{N} 2 \mathrm{O}$ and methane emissions.

In agriculture climate change mitigation of methane emission is very important. The strategies for mitigating methane emission from rice cultivation could be altering water management, particularly promoting mid-season aeration by short term drainage; improving organic matter management by promoting aerobic degradation through composting or incorporating it into soil during off-season drained period; use of rice cultivars with few unproductive tillers, high root oxidative activity, and high harvest index; and application of fermented manure like biogas slurry in place of unfermented farmyard manure.

\section{Climate change Mitigation through Organic Farming:}

Organic agriculture as a mitigation strategy addresses both emissions avoidance and carbon sequestration. Barton et al. (2008) reported that lower N2O emissions due to lower nitrogen input in of it is usually assumed that 1-2 percent of the nitrogen applied to farming systems is emitted as $\mathrm{N} 2 \mathrm{O}$, irrespective of the form of the nitrogen input. The default value currently used by the IPCC is 1.25 percent, but newer research finds considerably lower values, such as for semi-arid areas

IPCC, [6], Lal et al.[9] Van Oost et al. [13] Renwick et al. [11] note that less CO2 emissions through erosion due to better soil structure and more plant cover there usually is less erosion in organic farming systems than in conventional ones. The effect of erosion on $\mathrm{CO} 2$ emissions is still controversial, however and lowers $\mathrm{CO} 2$ emissions from farming system inputs pesticides and fertilizers produced using fossil fuel.

\section{Climate Change Coping Mechanism and Sustainable Agriculture:}

The practicing Climate Change coping mechanism is very important in achieving sustainable agriculture. The coping mechanism on increased flexibility of operations can be promoted in the form of technical infrastructure, cropping patterns and water management measures and they must be geared to allow for flexible operations. This enables quick and easy adjustments in water availability by adding water irrigation or draining as part of an adaptive water management system.

The next climate change coping mechanism is adaption of production systems. It could be noted that in coastal areas, salt water intrusion due to the rise of the sea level will cause salinisation and necessitate adapted production systems with plants that have a higher salt tolerance.

The third climate change coping mechanism is implementation of new cultivation methods. In this context, ridges, terraces or planting holes are new cultivation methods that help to catch or drain surface water. In combination with improved land management practices in the form of agroforestry, that can contribute to a reduction in soil erosion and improved livelihoods.

The fourth climate change coping mechanism is availability and utilization of of historical and prognostic data. The importance of data management related to water resources and their future dynamics must be given increased attention in the form of using new technologies, such as remote sensing.

The fifth climate change coping mechanism is consumer awareness and conservation. It can be in the form of clear water use rights and pricing will lead to more sustainable and considerate consumption and help to conserve the diminishing sources of freshwater.

The sixth climate change coping mechanism is more attention to demand management. It could be noted that options to increase water supply by greater water extraction from rivers, springs and groundwater or by storing seasonal excess water in large reservoirs will decrease in the long run. Instead, attempts to promote demand management by inducing farmers to use water more efficiently and to prevent non-beneficial losses will have to be given priority. 


\section{Conclusion:}

It could be seen clearly from the above discussion that the climate change adaptation is highly required towards achieving agriculture sustainability. The conventional agriculture practices are not suitable in the context of climate change. The sustainability of farming practice depends on prevention of climate change impact on cropping pattern and agronomy practices. Many climate change adaptation options and climate change mitigation options are discussed in this paper. Such climate change adaptation options and climate change mitigation options can sustain the agriculture production. It could be noted that agriculture production cannot be declined consequent up on climate change impact. The decline in agriculture production can adversely affect the food security and food need of the highly populated country like India. Hence, achieving sustainable agriculture productivity is urgent need of the hour in the context of climate change. In order to achieve sustainable agriculture production, the farmers should be made aware of the climate change impact and its consequent on agriculture yield. The farmers should be trained towards practicing climate change adaptation practices and mitigation measures towards overcome the negative impact of climate change on agriculture by the way of conducting awareness training programmes and awareness campaign.

\section{REFERENCES}

[1] Altieri, M.A., 1987. Agro-Ecology, The Scientific Basis of Alternative Agriculture, Westriew Press, Boulder.

[2] Barton, L., R. Kiese, D. Gatter, K. Butterbach-Bahl, R. Buck, C. Hinz and D. Murphy, 2008.

[3] Donald, L.P. and L.W. Donald, 1995. Technology for Sustainable Agriculture Science America, 273(33): $182-186$

[4] Group III Report: Mitigation of Climate Change." See specifically on agriculture, chapter 8.

[5] Hatfield, J., K. Boote, P. Fay, L. Hahn, et al., 2008. Agriculture. "The Effects of Climate Change on Agriculture, Land Resources, Water Resources, and Biodiversity in the United States.”.

[6] IPCC, 2007. "Summary for Policy Makers." In IPCC Fourth Assessment Report, "Working.

[7] Jones, M.J., 1993. in Crop Production and Sustainable Agriculture Chand Wich, D.J. and March J (eds), Wiley Chichester, pp: 30-40.

[8] Boote, K., P. Fay, L. Hahn, C. Izaurralde, et al., "Synthesis and Assessment Product 4.3." U.S. Department of Agriculture. Washington, DC, pp: 21-74.

[9] Lal, R., M. Griffin, J. Apt, L. Lave, and G. Morgan, 2004. "Managing Soil Carbon,” Science 304: 393; and "Response to Comments on 'Managing Soil Carbon," Science 305: 1567.

[10] Ministry of Environment, forest and climate change, 2009. Adaptation to Climate Change with a Focus on Rural Areas and India.

[11] Renwick, W., S. Smith, R. Sleezer and R. Buddemeier, 2004. Comment on "Managing Soil Carbon (II)," Science 305, no. 5690 (September 10, 2004): 1567. DOI: 10.1126/science.1100447.

[12] Shaller, N., 1990. Main Streaming Low Input Agriculture Journal of Soil, Water Conservation, 45: 9-12.

[13] Van Oost, K., G. Govers, T. Quine and G. Heckrath, 2004. "Comment on 'Managing Soil Carbon (I)," Science 305, no. 5690 (September 10, 2004): 1567. DOI: 10.1126/science.1100447. 